INFLAMMATION AND INFLAMMATORY BOWEL DISEASE

\title{
The locally acting glucocorticosteroid budesonide enhances intestinal sugar uptake following intestinal resection in rats
}

\author{
A Thiesen, G E Wild, K A Tappenden, L Drozdowski, M Keelan, B K A Thomson, \\ M I McBurney, M T Clandinin, A B R Thomson
}

See end of article for authors' affiliations

Correspondence to: A B R Thomson, 519 Newton Research Building, University of Alberta, Edmonton, AB T6G 2C2, Canada;

alan.thomson@ualberta.ca

Accepted for publication 25 June 2002

\begin{abstract}
Background and aims: Locally and systemically acting corticosteroids alter the morphology and transport function of the intestine. This study was undertaken to assess the effect of budesonide, prednisone, and dexamethasone on sugar uptake.

Methods: Adult male Sprague Dawley rats underwent transection or resection of $50 \%$ of the middle portion of the small intestine, and in vitro uptake of sugars was measured.

Results: The $50 \%$ enterectomy did not alter jejunal or ileal uptake of glucose or fructose. Prednisone had no effect on the uptake of glucose or fructose in resected animals. In contrast, in resected rats budesonide increased by over $120 \%$ the value of the jejunal maximal transport rate for the uptake of glucose, and increased by over 150\% ileal uptake of fructose. Protein abundance and mRNA expression of the sodium dependent glucose transporter in brush border membrane (SGLT1), sodium independent fructose transporter in the brush border membrane (GLUT5), sodium independent glucose and fructose transporter in the basolateral and brush border membranes (GLUT2), and $\mathrm{Na}^{+} / \mathrm{K}^{+}$ATPase $\alpha 1$ and $\beta 1$ did not explain the enhancing effect of budesonide on glucose or fructose uptake. Budesonide, prednisone, and dexamethasone reduced jejunal expression of the early response gene c-jun. In resected animals, expression of the mRNA of ornithine decarboxylase (ODC) in the jejunum was reduced, and corticosteroids reduced jejunal expression of the mRNA of proglucagon.

Conclusions: These data suggest that the influence of corticosteroids on sugar uptake in resected animals may be achieved by post translational processes involving signalling with c-jun, ODC, and proglucagon, or other as yet unknown signals. It remains to be determined whether budesonide may be useful to stimulate the absorption of sugars following intestinal resection in humans.
\end{abstract}

$\mathrm{T}$ he topic of intestinal adaptation has been reviewed. ${ }^{12}$ Following extensive intestinal resection, there is hyperplasia of the remaining intestine which may be accompanied by enhanced uptake of nutrients. ${ }^{3-8}$ Signals which mediate this adaptive process may include proglucagon derived peptides, ornithine decarboxylase (ODC), and early response genes (ERGs). ${ }^{9-13}$ Proglucagon derived peptides originate from processing and breakage of the proglucagon gene ${ }^{14}{ }^{15}$ in the $\mathrm{L}$ cells present in the ileum and colon. ${ }^{16}$ mRNA levels of proglucagon, ODC, as well as ERGs such as c-myc, c-jun, and c-fos have been suggested to be involved in the adaptive process of the remaining intestine after jejunoileal resection..$^{9-13}$ It is not known if proglucagon, ODC, or ERGs in the intestine are influenced by corticosteroids. Other possible signals have been recently identified by cDNA microarray analysis and may have a role in this intestinal adaptive model. ${ }^{17}{ }^{18}$

The $\mathrm{Na}^{+}$gradient across the brush border membrane (BBM) provides the driving force for glucose transport into the enterocyte. ${ }^{19}$ This gradient is maintained by the action of the $\mathrm{Na}^{+} / \mathrm{K}^{+}$ATPase which is restricted to the basolateral membrane (BLM) ${ }^{20}$ Sodium dependent glucose transporter in the brush border membrane (SGLT1) mediates BBM Na $/$ glucose cotransport, ${ }^{21-23}$ and the sodium independent glucose and fructose transporter in the BLM and BBM (GLUT2) mediates the facilitative $\mathrm{Na}^{+}$independent diffusion of glucose and fructose through the BLM, ${ }^{24}$ as well as possibly through the BBM. ${ }^{25-27}$ Fructose transport is by facilitated diffusion in the BBM mediated by sodium independent fructose transporter in the BBM (GLUT5). ${ }^{28-31}$

Systemically active glucocorticosteroids given by mouth enhance the intestinal absorption of sugars ${ }^{32} 33$ and accelerate the development of the intestine in early life. ${ }^{34}$ The locally acting corticosteroid budesonide, termed local due its 90\% first pass hepatic metabolism allowing only $10 \%$ of budesonide to reach the systemic circulation, is useful in the treatment of patients with Crohn's disease, with a superior adverse effect profile than non-locally acting glucocorticosteroids. ${ }^{35-38}$ In young rats with an intact intestinal tract, budesonide enhances the intestinal uptake of fructose and some lipids. ${ }^{39}$ While injection of dexamethasone reduces the DNA content of the bowel following intestinal resection, ${ }^{40}$ its effect on nutrient absorption is not known. Accordingly, this study was undertaken to test the hypothesis that glucocorticosteroids, specially budesonide, enhance the intestinal absorption of sugars following intestinal resection.

\section{METHODS}

\section{Animals and diet}

The principles for the care and use of laboratory animals approved by the Canadian Council on Animal Care and by the Council of the American Physiological Society were carefully

Abbreviations: BBM, brush border membrane; BLM, basolateral membrane; ERG, early response genes; GLUT5, sodium independent fructose transporter in the brush border membrane; GLUT2, sodium independent glucose and fructose transporter in the basolateral and brush border membranes; HRP, horseradish peroxidase; $\mathrm{Km}$, apparent Michaelis constant; ODC, ornithine decarboxylase; SGLT1, sodium dependent glucose transporter in brush border membrane; TTBS, Tween Tris buffered saline; Vmax, maximal transport rate. 
Table 1 Effect of steroids on the characteristics of the intestine of rats undergoing intestinal resection

\begin{tabular}{|c|c|c|c|}
\hline Site & Drug & $\begin{array}{l}\text { Intestinal weight } \\
(\mathrm{mg} / \mathrm{cm})\end{array}$ & $\begin{array}{l}\text { Intestinal wall comprised } \\
\text { of mucosa (\%) }\end{array}$ \\
\hline \multirow[t]{4}{*}{ Jejunum } & Control & $23.4(3.7)$ & $47.5(4.1)$ \\
\hline & Budesonide & 23.1 (2.3) & 48.7 (4.1) \\
\hline & Prednisone & $24.2(1.7)$ & $48.5(7.2)$ \\
\hline & Dexamethasone & 21.1 (2.5) & $64.2(2.4)$ \\
\hline \multirow[t]{4}{*}{ lleum } & Control & $17.5(4.8)$ & $46.4(4.7)$ \\
\hline & Budesonide & $14.5(0.7)$ & $40.4(6.0)$ \\
\hline & Prednisone & 13.5 (1.7) & $52.2(2.0)$ \\
\hline & Dexamethasone & $9.4(1.8)$ & $52.2(2.1)$ \\
\hline
\end{tabular}

Table 2 Effect of corticosteroids on the value of the maximal transport rate (Vmax) and the Michaelis affinity constant $(\mathrm{Km})$ of D-glucose in the jejunum and ileum of rats undergoing intestinal resection

\begin{tabular}{|c|c|c|c|c|}
\hline \multirow[b]{2}{*}{ Drug } & \multicolumn{2}{|l|}{ Jejunum } & \multicolumn{2}{|l|}{ Ileum } \\
\hline & Vmax & $\mathrm{Km}$ & $V_{\max }$ & $\mathrm{Km}$ \\
\hline Control & 3066 (217) & 39.7 (5.5) & $2726(320)$ & $59.7(11.9)$ \\
\hline Budesonide & $6790(803)^{*}$ & $93.7(16.5)^{*}$ & 5091 (964) & 131.1 (34.0) \\
\hline Prednisone & $2531(535) \dagger$ & $35.7(15.2) \dagger$ & 9354 (3313) & $239.3(102.8)$ \\
\hline Dexamethasone & $2991(283) \dagger$ & $39.3(7.3) \dagger$ & $5062(2464)$ & 118.3 (80.7) \\
\hline
\end{tabular}

Values are mean $(S E M) ; n=6$

$V \max$ (maximal transport rate) is given in $\mathrm{nmol} \times 100 \mathrm{mg} /$ tissue $/ \mathrm{min}$.

$\mathrm{Km}$ (Michaelis affinity constant) is given in $\mathrm{mM}$.

${ }^{*} p<0.05$, budesonide, prednisone, or dexamethasone versus control; $\uparrow p<0.05$, prednisone or

dexamethasone versus budesonide.

observed. Male pairs of Sprague Dawley rats were obtained from the University of Alberta Vivarium. Animals were housed in pairs at $21^{\circ} \mathrm{C}$, with 12 hours of light and 12 hours of darkness. They weighed 200-250 g. Water and food were supplied ad libitum. Animals were fed standard Purina rat chow for two weeks.

\section{Drugs}

The glucocorticosteroids (budesonide, prednisone, and dexamethasone) were given to animals with a $50 \%$ resection. There were six animals in each of four treatment groups: control vehicle (0.19\% EDTA buffered saline), budesonide $(0.25 \mathrm{mg} / \mathrm{kg}$ body weight per day), prednisone $(0.75 \mathrm{mg} / \mathrm{kg}$ body weight/ day), and dexamethasone ( $128 \mu \mathrm{g} / \mathrm{kg}$ body weight/day). This dose of budesonide has been shown to modify intestinal absorption of nutrients in young animals with an intact intestine and fed chow ${ }^{39}$ and is similar to doses $(0.2-0.8 \mathrm{mg} / \mathrm{kg} /$ day $)$ used to treat trinitrobenzene sulphonic acid ileitis in rats ${ }^{41}$ and prevent graft rejection $(0 .-1.0 \mathrm{mg} / \mathrm{kg} / \mathrm{day})$ in a rat model of intestinal transplantation. ${ }^{42}$ The control vehicle, budesonide, and prednisone were administrated by oral gavage and were dissolved in $0.19 \%$ EDTA buffered saline. Dexamethasone was administrated subcutaneously and was dissolved in bacteriostatic $0.9 \%$ sodium chloride solution. The volume of vehicle given was $5 \mu \mathrm{l} / \mathrm{g}$ body weight. Dosing was performed at 12:00 daily for two weeks, including weekends.

\section{Surgical model}

Rats were exposed to halothane $(5.0 \%)$ until limp, when the hair on the anterior abdominal wall was clipped and the skin was cleansed with betadine. Animals were kept sedated under halothane (0.5-1.5\%) throughout surgery. The sleeping animal was restrained in the supine position on an animal operating board using rubber band leg loops. A heating pad was maintained at $37^{\circ} \mathrm{C}$ under the operating board, with circulating water from a water bath during all subsequent surgical procedures. Following a ventral incision along the linea alba, the middle $50 \%$ of the small intestine was removed from half of the animals. The other half of the rats had a transection-that is, the small intestine was divided and then reanastomosedwithout removal of any portion of the intestine. Sterile instruments and an aseptic technique were used. The colon was located, and the distance from the ileocaecal valve to the ligament of Treitz was measured with 5-0 silk string. The string was cut in half to give the approximate measure of the length of intestine to be resected. The intestinal portion to be resected was determined by placing one end of the measuring string at $2 \mathrm{~cm}$ after the ileal-caecal valve (to prevent back flow of bacteria from the colon), and working the string along the intestine towards the jejunal end. In resected animals, $50 \%$ of the middle portion of the intestine was removed, leaving the proximal $25 \%$ and the distal 25\%. Bowel continuity was restored by an end to end jejunoileal anastomosis using interrupted 6-0 silk sutures. The abdomen was closed with a continuous 3.0 dexon suture. After surgery, animals received a subcutaneous injection of buprenorphine $0.01-0.05 \mathrm{mg} / \mathrm{kg}$ body weight for pain relief. Animals recovered in clean plastic cages under a heat lamp, and were then taken to fresh cages where they were housed individually.

\section{Probe and marker compounds}

$\left[{ }^{3} \mathrm{H}\right]$ inulin was used as a non-absorbable marker to correct for the adherent mucosal fluid volume. $\left[{ }^{14} \mathrm{C}\right]$ labelled probes included varying concentrations of D-glucose and D-fructose $(4,8,16,32$, and $64 \mathrm{mM})$. The concentration of L-glucose used was $16 \mathrm{mM}$. Unlabelled and $\left[{ }^{14} \mathrm{C}\right]$ labelled probes were supplied by Sigma (St Louis, Missouri, USA) and by New England Nuclear (Nellesley, Massachusetts, USA), respectively. Probes were shown by the manufacturer to be more than $99 \%$ pure by high performance liquid chromatography. 
Table 3 Effect of corticosteroids on the rate of uptake of D-fructose in rats undergoing intestinal resection

\begin{tabular}{lll}
\hline Drug & Jejunum & lleum \\
\hline Control & $31.9(1.5)$ & $26.5(2.8)$ \\
Budesonide & $30.4(2.3)$ & $45.0(3.8)^{\star}$ \\
Prednisone & $33.5(2.3)$ & $27.3(1.9) \dagger$ \\
Dexamethasone & $23.3(1.4)^{*} \dagger \ddagger$ & $23.2(1.5) \dagger$ \\
\hline
\end{tabular}

Values are mean (SEM); $n=6$.

Rates of uptake of D-fructose are expressed as nmol $\times 100 \mathrm{mg} /$ tissue/min. This represents the slope of the linear relationship between fructose concentration and uptake.

${ }^{*} p<0.05$, budesonide, prednisone, or dexamethasone versus control; $\dagger \mathrm{p}<0.05$, prednisone or dexamethasone versus budesonide; $\ddagger \mathrm{p}<0.05$, dexamethasone versus prednisone.

\section{Tissue preparation and determination of uptake rates} Uptake studies were performed two weeks after small bowel transection or resection. Animals were anaesthetised by intraperitoneal injection of Euthanyl (sodium pentobarbitol) 240 $\mathrm{mg} / \mathrm{l00} \mathrm{g}$ body weight. The whole length of the transected small intestine or small intestine remaining after enterectomy was removed quickly. The intestine was everted and cut into small rings of approximately $2-4 \mathrm{~mm}$ each. ${ }^{43}{ }^{44}$ These rings were immersed immediately in preincubation beakers containing oxygenated Krebs bicarbonate buffer $\left(\mathrm{pH} \mathrm{7.2)}\right.$ at $37^{\circ} \mathrm{C}$ and were allowed to equilibrate for approximately five minutes prior to commencement of the uptake studies. Uptake was initiated by the timed transfer of tissue rings to a shaking water bath $\left(37^{\circ} \mathrm{C}\right)$ containing $5 \mathrm{ml}$ plastic vials with gassed Krebs buffer plus $\left[{ }^{3} \mathrm{H}\right]$ inulin and $\left[{ }^{14} \mathrm{C}\right]$ labelled substrates. After incubation for five minutes, uptake of nutrient was terminated by pouring the vial contents onto filters on an Amicon vacuum filtration manifold maintained under suction. This was followed by washing the jejunal or ileal rings with ice cold saline. The dry weight of the tissue was determined, and the tissue was saponificated with $0.75 \mathrm{~N}$ $\mathrm{NaOH}$. Scintillation fluid was added, and radioactivity was determined by means of an external standardisation technique to correct for variable quenching of the two isotopes.

Rates of uptake were expressed as nmol of substrate taken up per $100 \mathrm{mg}$ dry weight of mucosa per minute $($ nmol $\times 100$ $\mathrm{mg} /$ tissue/min). Values from the four treatment groups are reported as mean (SEM) of the results from six animals in each of the four groups. Values for the maximal transport rate (Vmax) and Michaelis affinity constant $(\mathrm{Km})$ for glucose uptake were estimated by non-linear regression using the Sigma Plot program (Jandel Scientific, San Rafael, California, USA). Because of the linear nature of the relationship between fructose concentration and uptake, values of Vmax and $\mathrm{Km}$ could not be estimated. Instead, linear regression was used to estimate the value of the slope of the concentration versus uptake. One or two way analysis of variance and the Student's $t$ test were used to test the significance of the differences among animals treated with control vehicle, budesonide, prednisone, and dexamethasone. A p value of 0.05 or less was accepted as representing a statistically significant difference.

\section{Western immunoblotting}

BLM and BBM proteins from at least three animals in each group were separated by sodium dodecyl sulphatepolyacrylamide gel electrophoresis using a modification of the method developed by Laemmli (1970). After migration, proteins were immobilised on a solid support by electroblotting to a nitrocellulose membrane. Then, membranes were blocked by incubation overnight in bovine lacto transfer technique optimiser (BLOTTO) containing $5 \% \mathrm{w} / \mathrm{v}$ dry milk in Tween Tris buffered saline (TTBS: 0.5\% Tween 20, 30 mM Tris, $150 \mathrm{mM} \mathrm{NaCl}$ ).
A

\begin{tabular}{|c|c|c|c|}
\hline \multicolumn{4}{|c|}{ Ileum } \\
\hline \multicolumn{2}{|c|}{ SGLT1 } & \multicolumn{2}{|c|}{ Alpha 1} \\
\hline & $=$ & & E \\
\hline$R$ & $\mathrm{~T}$ & $R$ & $\mathrm{~T}$ \\
\hline \multicolumn{2}{|c|}{$\mathrm{n}=3$} & \multicolumn{2}{|c|}{$\mathrm{n}=3$} \\
\hline \multicolumn{2}{|c|}{$1.24(0.07)^{*}$} & \multicolumn{2}{|c|}{$0.64(0.18)^{*}$} \\
\hline \multicolumn{2}{|c|}{$1(0)$} & \multicolumn{2}{|c|}{$1(0)$} \\
\hline
\end{tabular}

B

\begin{tabular}{c} 
Alpha 1 \\
\hline $\mathrm{R} \quad \mathrm{T}$ \\
$\mathrm{n}=4$ \\
$0.59(0.28)^{*}$ \\
$1(0)$
\end{tabular}

Figure 1 (A) Effect of intestinal resection on ileal abundance of SGLT1 and the $\mathrm{Na}^{+} / \mathrm{K}^{+}$ATPase $\alpha 1$ subunit. (B) Effect of intestinal resection on jejunal mRNA expression of $\mathrm{Na}^{+} / \mathrm{K}^{+}$- ATPase $\alpha 1$. Values are mean (SD). SGLT1, sodium dependent glucose transporter in brush border membrane; Alpha $1, \mathrm{Na}^{+} / \mathrm{K}^{+}$ATPase $\alpha$ subunit in the basolateral membrane; $R$, resection; $T$, transected. Ratio of resected versus transected animals. $n=$ sample size. ${ }^{\star} p<0.05$, resected versus transected.

Membranes were washed three times with TTBS for at least 10 minutes. Then, membranes were probed with specific rabbit antirat antibodies that bound specifically to the antigens of interest. Incubation was carried out at room temperature for two hours for $\alpha \mathrm{l} \mathrm{Na} / \mathrm{K}^{+}$ATPase, $\beta 1 \mathrm{Na}^{+} / \mathrm{K}^{+}$ATPase, GLUT2, and GLUT5, and overnight for SGLT1. Antibodies were diluted in $2 \%$ dry milk in TTBS at $1: 500$ for $\alpha 1 \mathrm{Na}^{+} / \mathrm{K}^{+}$ATPase, GLUT2, GLUT5, and SGLT1, and at $1: 2000$ for $\beta 1 \mathrm{Na}^{+} / \mathrm{K}^{+}$ATPase.

Polyclonal antibodies against SGLT1 and GLUT2 were obtained from Biogenesis (Poole, UK). Polyclonal antibody against GLUT5 was obtained from Chemicon International Inc. (Temecula, California, USA). The polyclonal antibodies antirat $\alpha \mathrm{l}$ and $\beta 1 \mathrm{Na}^{+} / \mathrm{K}^{+}$ATPase were obtained from Upstate Biotechnology Inc. (Lake Placid, NY, USA).

Following this primary incubation, BBM and BLM were washed three times with TTBS to remove residual unbound primary antibody. Membranes were then incubated for one hour with goat antirabbit antibody, conjugated with horseradish peroxidase (HRP) (Pierce, Rockfort, Illinois, USA) that bound the primary antibody. This second antibody was diluted at $1: 20000$ in $2 \%$ dry milk in TTBS.

After three washes in TTBS to remove residual secondary antibody, membranes were incubated for five minutes with SuperSignal chemiluminescent-HRP substrate (Pierce) composed of $50 \%$ stable peroxide solution and 50\% luminol/ enhancer solution. This reacted with the secondary antibody and made visible the antigens of interest. Then, membranes were exposed to X-Omat AR films for various times, and were successively plunged into developer, water, and fixer. Relative band densities were determined by transmittance densitometry using a Bio-Rad imaging densitometer (Life Science Group, Cleveland, Ohio, USA).

\section{Northern immunoblotting}

Complementary DNA (cDNA) probes were produced. Bacteria (Escherichia coli) were transformed with plasmids containing the desired DNA sequences to be used to probe for northern blotting. SGLTl cDNA probe was donated by Dr Davidson (University of Chicago, Chicago, Illinois, USA); cDNA probes encoding the $\alpha \mathrm{l}$ and $\beta \mathrm{l} \mathrm{Na} \mathrm{Na}^{+} / \mathrm{K}^{+}$ATPase subunit isoforms were 


\begin{tabular}{|c|c|c|c|c|c|c|c|c|c|c|c|}
\hline \multirow[b]{2}{*}{ Drug } & \multicolumn{5}{|c|}{ Jejunum } & \multicolumn{6}{|c|}{ Ileum } \\
\hline & \multicolumn{2}{|r|}{ SGLT1 } & Alpha 1 & \multicolumn{2}{|r|}{ Beta 1} & \multicolumn{2}{|r|}{ SGLT1 } & \multicolumn{2}{|c|}{ Alpha 1} & \multicolumn{2}{|r|}{ Beta 1} \\
\hline & \multicolumn{2}{|c|}{ 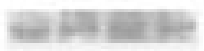 } & & \multicolumn{2}{|c|}{ 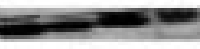 } & \multicolumn{2}{|r|}{100} & \multicolumn{2}{|c|}{$-\infty-$} & & $a=$ \\
\hline & D & $P \quad B \quad C$ & $D \quad P \quad B \quad C$ & $\mathrm{D}$ & P B C & $\mathrm{D}$ & $P \quad B \quad C$ & $\mathrm{D}$ & P B C & $\mathrm{D}$ & $P \quad B \quad C$ \\
\hline Control & \multicolumn{2}{|r|}{$\mathrm{n}=3$} & $\mathrm{n}=3$ & \multicolumn{2}{|r|}{$\mathrm{n}=3$} & \multicolumn{2}{|r|}{$\mathrm{n}=3$} & \multicolumn{2}{|r|}{$n=3$} & \multicolumn{2}{|r|}{$\mathrm{n}=3$} \\
\hline Budesonide & & $.66(0.65)$ & $0.82(0.15)$ & \multicolumn{2}{|c|}{$1.02(0.07)$} & \multicolumn{2}{|r|}{$0.91(0.37)$} & \multicolumn{2}{|c|}{$4.22(2.55)$} & \multicolumn{2}{|c|}{$1.39(0.02)^{*}$} \\
\hline Prednisone & & $.73(0.51)$ & $0.40(0.51)$ & \multicolumn{2}{|r|}{$1.09(1.28)$} & \multicolumn{2}{|r|}{$1.18(0.19)$} & \multicolumn{2}{|c|}{$2.00(2.25)$} & \multicolumn{2}{|r|}{$0.93(0.19) \dagger$} \\
\hline Dexamethasone & & $.08(0.15)$ & $0.45(0.62)$ & \multicolumn{2}{|r|}{$0.89(0.98)$} & \multicolumn{2}{|r|}{$0.79(0.20)$} & \multicolumn{2}{|c|}{$3.44(1.15)$} & \multicolumn{2}{|c|}{$1.29(0.03)^{* \ddagger}$} \\
\hline
\end{tabular}

Figure 2 Effect of corticosteroids on abundance of SGLT1 and $\mathrm{Na}^{+} / \mathrm{K}^{+}$ATPase $\alpha 1$ and $\beta 1$ subunits. Values are mean (SD). SGLT1, sodium

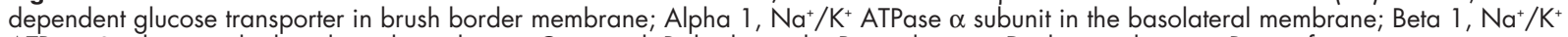
ATPase $\beta$ subunit in the basolateral membrane. $C$, control; $B$, budesonide; $P$, prednisone; $D$, dexamethasone. Ratio of treatment (glucocorticosteroids) versus control animals. $n=$ sample size. ${ }^{*} p<0.05$, budesonide, prednisone, or dexamethasone versus control; $\dagger p<0.05$, prednisone or dexamethasone versus budesonide; $\ddagger p<0.05$, dexamethasone versus prednisone.

obtained from Dr Lingrel (University of Cincinnati, Cincinnati, Ohio, USA); cDNA probes encoding GLUT5 and GLUT2 were obtained from Dr Bell (University of Chicago, Chicago, Illinois, USA); ERG probes were obtained from Oncogene Research Products (San Diego, California, USA); cDNA probe encoding proglucagon was obtained form Dr Fuller (Prince Henry's Institute of Medical Research, Melbourne, Australia); and ODC was obtained from Dr Blackshear (University of Chicago, Chicago, Illinois, USA).

RNA was extracted from the jejunum and ileum of at least three animals in each of four groups. These segments were homogenised in a denaturing solution containing guanidinium thiocyanate using the Bio-Rad fast prep shaking centrifuge. Following acidification with $2 \mathrm{M}$ sodium acetate, phenol chloroform extraction was performed. The upper aqueous phase was transferred to a tube and RNA was precipitated with isopropanol and washed with $70 \%$ ethanol. RNA samples were stored at $-70^{\circ} \mathrm{C}$.

Equal amounts of total RNA were denatured in a sample loading buffer. Ethidium bromide $(10 \mathrm{mg} / \mathrm{ml})$ was added so that the integrity of the RNA could be determined by visualising the $28 \mathrm{~S}$ and $18 \mathrm{~S}$ ribosomal bands under UV light.

Total RNA was separated, based on molecular weight, as it was electrophoresed through a denaturing agarose gel (1.16\% agarose). RNA was transferred from the gel to a nylon membrane by capillary action overnight.

As a prehybridisation step, membranes were incubated for 30 minutes with DIG easy hyb solution (Roche Diagnostics, Quebec, Canada) in order to reduce non-specific binding. Following prehybridisation, labelled probes were hybridised to the corresponding RNA band on the membrane by incubation with the DIG labelled probe at the adequate temperature overnight. After stringency washes, membranes were blocked in $1 \times$ blocking solution ( $10 \%$ 10xblocking solution, $90 \%$ $1 \times$ maleic acid) to reduce non-specific binding sites. They were then incubated with an anti-DIG-AP conjugate antibody (Roche Diagnostics).

Detection of bound antibody was done using a CDP-STAR chemiluminescent substrate (Roche Diagnostics), and membranes were exposed to films (X-Omat; Kodak, USA) for 10-30 minutes. The density of the RNA was determined by transmittance densitometry using a Bio-Rad imaging densitometer (Life Science Group, Cleveland, Ohio, USA). To determine the exact RNA quantity that had been loaded, the $28 \mathrm{~S}$ ribosomal band density on the membrane was evaluated after transfer.

\section{RESULTS}

Animal characteristics

Body weight gain, food intake, and weight gain (g/day) per food intake (g/day) were similar in transected and resected

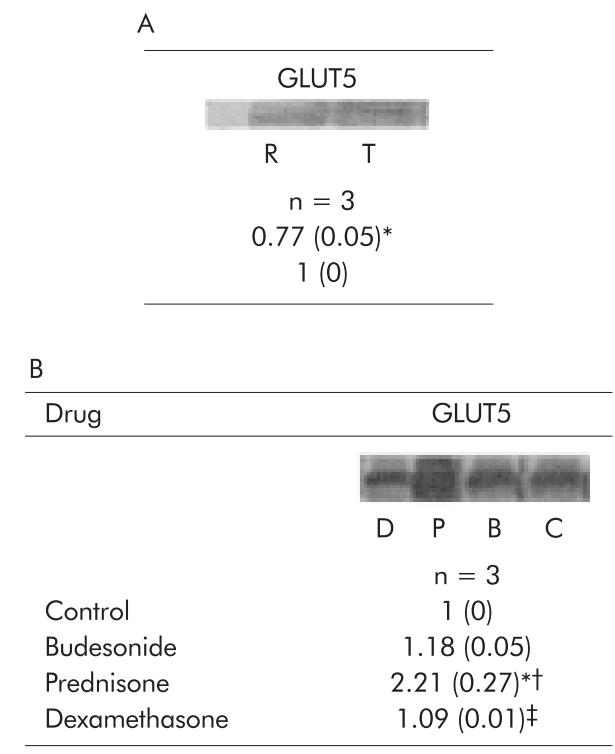

Figure 3 (A) Effect of intestinal resection on jejunal mRNA expression of GLUT5. (B) Effect of corticosteroids on jejunal mRNA expression of GLUT5 of rats undergoing intestinal resection. Values are mean (SD). $n=$ sample size. GLUT5, sodium independent fructose transporter in the brush border membrane. In (A), R=resection,

$T=$ transected. Ratio of resected versus transected animals. ${ }^{*} p<0.05$, resected versus transected. In (B) $C=$ control, $B=$ budesonide, $\mathrm{P}=$ prednisone and $\mathrm{D}=$ dexamethasone. Ratio of treatment (glucocorticosteroids) versus control animals. ${ }^{*} p<0.05$, budesonide, prednisone, or dexamethasone versus control; $\nmid p<0.05$, prednisone or dexamethasone versus budesonide; $\ddagger p<0.05$, dexamethasone versus prednisone.

rats (data not shown). Dexamethasone reduced body weight gain in resected animals (from $4.8 \mathrm{~g}$ /day in controls to 2.0 $\mathrm{g}$ /day in those given dexamethasone) whereas budesonide and prednisone had no such effect. None of the steroids influenced food intake.

The total weight of the intestine and the percentage of the intestinal wall comprised of scrapable mucosa were similar in the jejunum and ileum of resected and transected rats (data not shown). Similarly, in resected rats budesonide, prednisone, or dexamethasone had no effect on the weight of the intestine or on the percentage of the intestinal wall comprised of mucosa (table 1). For this reason, the rates of sugar uptake were expressed on the basis of intestinal weight (nmol $\times 100$ $\mathrm{mg} /$ tissue/min).

\section{Transporter activities}

There was no effect of resection of the middle half of the intestine on values of maximal transport rate (Vmax) and 
Table 4 Effect of corticosteroids on expression of mRNAs for the early response genes of rats undergoing intestinal resection

\begin{tabular}{|c|c|c|c|c|c|c|}
\hline \multirow[b]{2}{*}{ Drug } & \multicolumn{3}{|l|}{ Jejunum } & \multicolumn{3}{|l|}{ Ileum } \\
\hline & $c-m y c$ & $c$-jun & c-fos & c-myc & $c$-jun & $c-f o s$ \\
\hline Control & $1(0)$ & 110 & NS & $1(0)$ & $1(0)$ & NS \\
\hline Budesonide & $1.08(0.70)$ & $0.43(0.02)$ * & NS & $0.83(0.23)$ & $0.99(0.54)$ & NS \\
\hline Prednisone & 1.84 (1.83) & $0.46(0.02)$ * & NS & $1.22(0.48)$ & $1.42(1.00)$ & NS \\
\hline Dexamethasone & 1.03 (0.79) & $0.54(0.11)^{*}$ & NS & $1.06(0.14)$ & $1.02(0.18)$ & NS \\
\hline
\end{tabular}

Values are mean $(S D) ; n=3$.

Ratio of treatment (glucocorticosteroids) versus control animals.

${ }^{*} \mathrm{p}<0.05$, budesonide, prednisone or dexamethasone versus control; NS, no signal.

\begin{tabular}{|c|c|c|c|c|}
\hline & \multicolumn{2}{|l|}{ Jejunum } & \multicolumn{2}{|l|}{ lleum } \\
\hline & Proglucagon & ODC & Proglucagon & ODC \\
\hline Transected & $1(0)$ & $1(0)$ & $1(0)$ & $1(0)$ \\
\hline Resected & $1.10(0.09)$ & $0.52(0.12)^{*}$ & $0.98(0.11)$ & $0.85(0.16)$ \\
\hline
\end{tabular}

Table 6 Effect of corticosteroids on expression of mRNAs for proglucagon and ornithine decarboxylase $(O D C)$ of rats undergoing intestinal resection

\begin{tabular}{|c|c|c|c|c|}
\hline & \multicolumn{2}{|l|}{ Jejunum } & \multicolumn{2}{|l|}{ Ileum } \\
\hline & Proglucagon & ODC & Proglucagon & ODC \\
\hline Control & $1(0)$ & $1(0)$ & $1(0)$ & $1(0)$ \\
\hline Budesonide & $0.49(0.08)$ * & $1.02(0.49)$ & $1.01(0.10)$ & $0.81(0.20)$ \\
\hline Prednisone & $0.46(0.08)^{*}$ & $1.12(0.72)$ & 1.01 (0.18) & $0.84(0.11)$ \\
\hline Dexamethasone & $0.44(0.01)^{*}$ & $0.78(0.24)$ & $0.88(0.22)$ & $0.82(0.05)$ \\
\hline
\end{tabular}

Values are mean (SD); $n=3$

Ratio of treatment (glucocorticosteroids) versus control animals.

${ }^{*} p<0.05$, budesonide, prednisone, or dexamethasone versus control.

apparent Michaelis constant (Km) for jejunal or ileal uptake of glucose (data not shown). However, values of Vmax and $\mathrm{Km}$ for jejunal uptake of glucose were both approximately 120\% higher in rats given budesonide compared with control vehicle (table 2). Values of Vmax and Km for jejunal uptake of glucose in resected rats were lower in those given prednisone or dexamethasone compared with budesonide. None of the corticosteroids had an effect on Vmax or Km for ileal uptake of glucose. Resection had no effect on the rates of jejunal and ileal uptake of L-glucose. Similarly, corticosteroids had no effect on L-glucose uptake into the jejunum (data not shown).

Resection had no effect on uptake of fructose into the jejunum or ileum (data not shown). In the jejunum of resected rats, dexamethasone reduced uptake of fructose by approximately $27 \%$ compared with control vehicle, budesonide, or prednisone (table 3). In the ileum of resected rats, budesonide increased the uptake of fructose by 100\% compared with control vehicle, prednisone, or dexamethasone.

\section{Transporter protein abundance and expression of mRNA}

Protein abundance SGLTl and $\mathrm{Na}^{+} / \mathrm{K}^{+}$ATPase $\alpha \mathrm{l}$ and $\beta 1$ in the jejunum was not altered by intestinal resection. However, in the ileum, abundance of SGLTl was increased by resection whereas $\mathrm{Na}^{+} / \mathrm{K}^{+}$ATPase $\alpha \mathrm{l}$ was reduced and $\mathrm{Na}^{+} / \mathrm{K}^{+}$ATPase $\beta \mathrm{l}$ was unchanged. Resection did not change jejunal or ileal mRNA expression of SGLTl or $\mathrm{Na}^{+} / \mathrm{K}^{+}$ATPase $\beta 1$ but $\mathrm{Na}^{+} / \mathrm{K}^{+}$
ATPase $\alpha 1$ mRNA expression in the ileum was reduced by resection in the ileum (fig $1 \mathrm{~A}$ ). In the ileum, budesonide and dexamethasone increased the abundance of $\mathrm{Na}^{+} / \mathrm{K}^{+}$ATPase $\beta 1$ compared with the control vehicle and prednisone group. In animals with resection, corticosteroids had no effect on mRNA expression of SGLTl or $\mathrm{Na}^{+} / \mathrm{K}^{+}$ATPase in the jejunum and ileum (fig lB). Budesonide, prednisone, or dexamethasone administrated to resected animals did not change jejunal abundance of SGLTl, or either of the $\mathrm{Na}^{+} / \mathrm{K}^{+}$ATPase subunits (fig 2).

Resection did not have any significant effect on the abundance of GLUT5 or GLUT2 (data not shown). Expression of GLUT5 mRNA was reduced in the jejunum of resected compared with transected animals, and was unchanged in the ileum (fig 3A). GLUT2 mRNA was unchanged with resection. Corticosteroids did not affect the protein abundance of either GLUT5 or GLUT2 (data not shown). Prednisone increased mRNA expression of GLUT5 in the jejunum of resected animals compared with transected controls (fig 3B). Expression of GLUT5 mRNA in the ileum, and GLUT2 mRNA in either the jejunum and ileum, were unchanged by administration of corticosteroid.

\section{Early response gene expression}

Animals undergoing intestinal resection showed no differences in expression of mRNAs for c-myc or c-jun compared with those who underwent transection (data not shown). 
Budesonide, prednisone, and dexamethasone reduced jejunal expression of the mRNA of c-jun in resected animals (table 4). No differences were observed in jejunal expression of c-myc or ileal expression of c-myc and c-jun.

\section{Proglucagon and ODC expression}

Expression in the jejunum and ileum of mRNA for proglucagon was not changed by resection. However, ODC expression in the jejunum of resected animals was reduced (table 5). No changes in ileal expression of the mRNA for ODC were observed. Corticosteroids reduced jejunal expression of the mRNA for proglucagon in resected animals compared with control vehicle but did not change ileal expression. Corticosteroids had no effect on jejunal or ileal expression of mRNA for ODC (table 6).

\section{DISCUSSION}

We chose a protocol of non-massive intestinal resection (50\%) where the remaining proximal and distal intestinal remnants were adequate to assess the morphology and function at these sites. $^{45}$ This 50\% resection did not result in body weight loss, and is closer to the more common clinical situation seen for example in patients with Crohn's disease. In this study, the animals' food intake, body weight gain, intestinal weight, and percentage of intestinal weight comprised of mucosa were unaffected by intestinal resection. Thus the alterations in the function of the non-resected intestine in animals given steroids were not due to changes in these end points.

Intestinal absorption of nutrients is subject to adaptation of mediated and non-mediated processes, with alterations in transport influenced by the animal's age, diet, as well as by pathological processes such as diabetes mellitus, chronic ethanol intake, and abdominal irradiation. ${ }^{12}$ Following intestinal resection, morphological and functional changes occur depending on the extent of the intestine removed, the site studied, and the lipid content of the diet. ${ }^{45}$ Signals for this process are unknown but may include proglucagon derived peptides, ERGs, and ODC. ${ }^{9-13}$ 46-49 ERGs such as c-myc, c-jun, and c-fos have been demonstrated to be involved in processes of intestinal proliferation and differentiation, as also is ODC, a key enzyme in the synthesis of polyamines which are a requirement in any proliferative event. ${ }^{9-13}$ Proglucagon also contributes to the intestinal adaptive process. ${ }^{14}{ }^{15}$ For example, administration of short chain fatty acids increases proglucagon mRNA expression in rats undergoing intestinal resection. ${ }^{13}$ In this study, the adaptive response to intestinal resection did not change expression of the mRNAs for ERGs or proglucagon but ODC mRNA was reduced in the jejunum of resected rats. Adaptation in sugar absorption following intestinal resection must involve other signals. Epimorphin/ syntaxin 2 mRNA that codes for a membrane associated protein involved in morphogenesis of the lungs and skin, and PC4/TIS7, a gene involved in nerve growth factor mediated cytodifferentiation, may be among other signals that might be involved in the adaptive response after intestinal resection. ${ }^{50}{ }^{51} \mathrm{New}$ signals involved in the adaptive intestinal response after resection have recently been identified by cDNA microarray analysis. ${ }^{17} 18$

Glucocorticosteroids are used to treat patients with a variety of intestinal conditions, including Crohn's disease and ulcerative colitis. Clinical studies have focused on the use of the potent locally acting steroid, budesonide. ${ }^{35-38}$ Prednisone and budesonide modify the morphology and absorptive function of the intestine in young rats with an intact intestinal tract. ${ }^{39}$ Corticosteroids may have metabolic (for example, glutamine) and/or functional (for example, electrolyte transport) actions that could explain effects on intestinal absorption. Furthermore, the effect of glucocorticosteroids on cell renewal rate and apoptosis as well as central effects could also in principle alter gut function. ${ }^{32} 33852$ This study compared the influence of the locally active budesonide with two systemically active corticosteroids (prednisone given by mouth and dexamethasone given by subcutaneous injection) in adult animals in which a portion of the jejunum and ileum remained after removal of the middle half of the small intestine.

Although we used the same dose of dexamethasone (128 $\mu \mathrm{g} / \mathrm{kg}$ subcutaneously) which has been reported previously to blunt the expected increase in the bowel content of DNA one week after an $80 \%$ enterectomy, ${ }^{40}$ we were unable to demonstrate any adverse effect of dexamethasone on the weight of the jejunum or ileum of $50 \%$ resected animals. This lack of detrimental effect of dexamethasone may have been due to differences in animal strain, their age, length of intestine resected $(50 \% v 80 \%)$, time after resection when our studies were performed, or total dose of dexamethasone used. In resected animals, neither budesonide nor prednisone altered the weight of the intestine, or the percentage of the intestinal wall comprised of mucosa. It is possible that had we subjected the animals to a massive bowel resection ( $80 \%$ of the small bowel removed), the weight of the remaining intestine per unit length or surface area might have increased. None the less, based on these data, two weeks following a 50\% enterectomy, it is clear that these corticosteroids given in these doses and by these routes had no adverse effects on the weight of the intestine. Thus the data suggest that the effects of corticosteroids on the absorptive functions of the intestine, to be discussed, were not due to any corticosteroid induced change in the mass of the intestine.

While absorption of some nutrients may be increased after intestinal resection, the magnitude of this effect depends on the extent of resection, site and time after surgery when uptake experiments are performed, as well as the manner of the expression of the data. ${ }^{73-55}$ With removal of the middle half of the small intestine in this study, there was no change in the uptake of D-glucose (table 2), L-glucose, or D-fructose (data not shown) compared with transected animals. We could have subjected the animals to a massive small bowel resection and potentially been able to show enhanced uptake of sugars. However, interpretation of the results would then have been more difficult because of the expected concomitant changes in food intake, body weight gain, and intestinal weight. Furthermore, we wished these studies to have some potential clinical relevance. For example, in patients with Crohn's disease, prednisone or budesonide may be used therapeutically in doses similar to those used in this study, and while many of these individuals may have previously undergone an intestinal resection, massive resections would be unusual.

The doses of prednisone and budesonide used in this study were chosen on the basis of regimens which have been shown to be clinically useful in humans. ${ }^{35}{ }^{3756}$ The dose used has been shown to modify intestinal absorption of fructose and some lipids in chow fed rats with an intact intestine. ${ }^{39}$ There is a difference in the potency of various corticosteroids on absorption of sugars after a 50\% enterectomy: prednisone had no influence on the Vmax of glucose uptake or on uptake of fructose whereas budesonide increased by over $120 \%$ the value of Vmax for jejunal uptake of D-glucose (table 2). Also, budesonide increased by $70 \%$ ileal uptake of fructose (table 3 ). This occurred without any change in the non-mediated passive component of sugar uptake, as measured with L-glucose. Thus the locally active steroid budesonide accelerated intestinal absorption of these two sugars following intestinal resection.

Carrier mediated uptake is usually characterised by two kinetic constants: the maximal transport rate (Vmax) and Michaelis-Menton constant $(\mathrm{Km})$ that corresponds to that concentration of solute that will give one half Vmax and represents solute binding affinity. Our findings showed a change in Vmax and Km for glucose uptake (table 2) suggesting that the number of transporters per enterocyte increases, and the 
characteristics of the protein may change also. For this reason we proceeded and performed western and northern blots, as discussed bellow. Other possibilities that could explain the findings in Vmax and $\mathrm{Km}$ are also discussed.

Protein abundance and mRNA expression of the transporters responsible for BBM uptake of glucose and fructose (SGLT1 and GLUT5, respectively) did not correlate with changes in the activity of these transporters. For instance, enhanced jejunal glucose uptake with budesonide (table 2) was not accompanied by an increase in the abundance of SGLTl or its mRNA. Also, enhanced fructose uptake with budesonide in the ileum (table 3) was not accompanied by changes in GLUT5 abundance or mRNA expression. The reason for having only three animals in some of the studies was due to the fact that the uptake studies required a large amount of tissue $(n=6)$, and there was not always sufficient amounts of tissue left to be able to perform larger numbers of the western and northern blots. Therefore, our negative results should be carefully considered, and we cannot discard the possibility that there were small changes in gene expression which we were unable to demonstrate given the small sample size. We did not perform immunohistochemistry of SGLTl or GLUT5 and therefore it is possible that corticosteroids may modify sugar uptake by changing the distribution of these transporters along the villus, thereby increasing uptake without any variation in the total abundance of transporters. Also, Kellett et al have provided evidence to suggest that under some circumstances when the activity of SGLTl is stimulated, the increased cytosolic levels of protein kinase C $\beta I I$ facilitate trafficking of GLUT2 to the BBM thereby providing an additional transporter for glucose and fructose. ${ }^{26-30} 57$ Thus it is possible that a post-translational event is involved in the regulation of sugar uptake in response to administration of corticosteroids.

Although the systemic bioavailability of budesonide is approximately one order of magnitude lower than that for prednisone, its potency is much higher. ${ }^{35} 373955$ We speculate that the stimulating effect of budesonide on the jejunal uptake of glucose by SGLT1 and ileal uptake of fructose by GLUT5 is the result of its greater effect on the enterocyte receptors for glucocorticosteroids. This adaptive response with budesonide following intestinal resection may be important to maintain the well being of the animal. The glucose and fructose absorption promoting effect of budesonide following intestinal resection may prove to be a useful agent to enhance the intestinal adaptive response.

\section{ACKNOWLEDGEMENTS}

The authors wish to thank Kim Doring, Rob Drummond, Elizabeth Jarocka-Cyrta, Daphne Samuel, Elizabeth Wierzbicki, Mika Wierzbicki, and Muriel Guelly for their help and technical assistance. The financial support of the Medical Research Council of Canada and of AstraZeneca Canada Inc. (former Astra Pharm Inc.) was greatly appreciated. We thank Ciencia Laboratorio Medico (Brasil) and CAPES for the support of Dr Aducio Thiesen. Dr MT Clandinin wishes to acknowledge the generous support of the National Science and Engineering Research Council of Canada. Dr G Wild is a research scholar of Les Fonds de la Recherche en Sante du Quebec

\section{Authors' affiliations}

A Thiesen, L Drozdowski, M Keelan, B K A Thomson, A B R Thomson, Nutrition and Metabolism Research Group, Division of Gastroenterology, Department of Medicine, University of Alberta, Edmonton, Canada

G E Wild, Division of Gastroenterology, and Department of Anatomy and Cell Biology, McGill University, Montreal, Quebec, Canada K A Tappenden, Department of Agriculture, Food, and Nutritional Science, University of Alberta, Edmonton, Canada

M I McBurney, WK Kellogg Institute, Kellogg Company, Battle Creek, MI 49010-3232, USA

M T Clandinin, Nutrition and Metabolism Research Group, Division of Gastroenterology, Department of Medicine, and Department of Agriculture, Food and Nutritional Science, University of Alberta,

\section{Edmonton, Canada}

All authors are members of the Cell and Molecular Biology Collaborative Network in Gastrointestinal Physiology

\section{REFERENCES}

1 Thomson ABR, Keelan M, Wild G. Nutrients and intestinal adaptation. Clin Invest Med 1996;19:331-45.

2 Thomson ABR, Wild G. Adaptation of intestinal nutrient transport in health and disease. (Part 1 and 2). Dig Dis Scil 997:42:453-80.

3 Dowling RH, Booth CC. Structural and functional changes following small intestinal resection in the rat. Clin Sci 1967;56:139-49.

4 Weiser MM. Intestinal epithelial cell surface membrane glycoprotein synthesis. An indicator of cellular differentiation. J Biol Chem 1973;248:2542-8

5 Kinter IS, Wilson TH. Autoradiographic study of sugar and amino acid transport by everted sacs of hamster intestine. J Cell Biol 1975;25:19.

6 Garvey TQ, Human PE, Isselbacher KJ. Y-glutamyl transpeptidase of the rat intestine: localization and possible role in amino acid transport. Gastroenterology 1976;71:778-85.

7 Hanson WR, Osborne JW, Sharp JG. Compensation by the residual intestine after intestinal resection in the rat: I. Influence of amount of tissue removed. Gastroenterology 1977;72:692-700.

8 King IS, Sepulveda FM, Smith MW. Cellular distribution of neutral and basic amino acid transport system in rabbit ileal mucosa. J Physiol 1981;319:355-68.

9 Bristol JB, Williamson RCS. Mechanism of intestinal adaptation. Pediatr Surg Int 1988;4:233-41

10 Bloom SR, Polak JM. The hormonal pattern of intestinal adaptation: a major role for enteroglucagon. Scand J Gastroenterol 1982;14(suppl 74):93-103

11 Sagor GR, Ghatei MA, Al-Mukhtar MYT, et al. Evidence for a humoral mechanism after small intestinal resection: exclusion of gastrin but not enteroglucagon. Gastroenterology 1983;84:902-6.

12 Rountree DB, Ulshen MH, Selub S, et al. Nutrient-independent increases in proglucagon and ornithine decarboxylase messenger RNAs after jejunoileal resection. Gastroenterology 1992;103:462-8.

13 Tappenden KA, McBurney MI. Systemic short-chain fatty acids rapidly alter gastrointestinal structure, function, and expression of early response genes. Dig Dis Sci 1998:43:1526-36.

14 Mojsov S, Heinrich G, Wilson IB, et al. Preproglucagon gene expression in pancreas and intestine diversifies at the level of post-translational processing. J Biol Chem 1986;261:11880-9

15 Orskov C, Holst JJ, Poulsen SS, et al. Pancreatic and intestinal processing of proglucagon in man. Diabetology 1987;30:873-81.

16 Larsson L-I, Holst J, Hakanson R, et al. Distribution and properties of glucagon immunoreactivity in the digestive tract of various mammals: an immunohistochemical and immunochemical study. Histochemistry 1975;44:281-90

17 Erwin CR, Falcone RA, Stern LE, et al. Analysis of intestinal adaptation gene expression by cDNA expression arrays. J Parenter Enteral Nutr 2000;24:311-16.

18 Stern LE, Erwin CR, Falcone RA, et al. cDNA microarray analysis of adapting bowel after intestinal resection. J Pediatr Surg 2001;36:190-5.

19 Ricklis E, Quastel JH. Effects of cations on sugar absorption by isolated surviving guinea pig intestine. Can J Biochem Physiol 1958;36:347.

20 Hirayama BA, Smith CD, Wright EM. Secondary structure of the $\mathrm{Na}^{+}$/glucose cotransporter. J Gen Physiol 1992;100:19-20.

21 Vehyl M, Puschel B, Spangenberg J, et al. Cloning of the $\beta$-subunit of the $\mathrm{Na}^{+} / \mathrm{D}$-glucose symporter. FASEB J 1992;6:A1459.

22 Vehyl M, Spangenberg J, Phchel B, et al. Cloning of a membrane-associated protein which modifies activity and properties of the $\mathrm{Na}^{+} / \mathrm{D}$-glucose cotransporter. J Biochem 1993;268:25041-53.

23 Weber WM, PuschelB, Steffgen J, et al. Comparison of a $\mathrm{Na}^{+} / \mathrm{D}$-glucose transporter form rat intestine expressed in oocytes of Xenopus laevis with the endogenous cotransporter. Biochim Biophys Acta 1991;1063:7380.

24 Kellet GL, Helliwell PA. The diffusive component of intestinal glucose absorption is mediated by the glucose-induced recruitment of GLUT2 to the brush-border membrane. Biochem J 2000;350:155-62.

25 Helliwell PA, Richardson M, Affleck J, et al. Regulation of GLUT5, GLUT2 and intestinal brush-border fructose absorption by the extra-cellular signal-regulated kinase, p38 mitogen-activated kinase and phosphatidylinositol 3-kinase intracellular signalling pathways: implications for adaptation to diabetes. Biochem J 2000;350:163-9

26 Helliwell PA, Richardson M, Affleck J, et al. Stimulation of fructose transport across the intestinal brush-border membrane by PMA is mediated by GLUT2 and dynamically regulated by protein kinase $C$. Biochem J 2000;350: 149-54.

27 Kellet GL. The facilitated component of intestinal glucose absorption. J Physiol 2001;531:585-95.

28 Burant CF, Bell Gl. Facilitative glucose transporters: evidence for similar substrate binding sites in functionally monomeric proteins. Biochemistry 1992:31:10414-20.

29 Burant CF, Takeda J, Brot-Laroche E, et al. Fructose transporter in human spermatozoa and small intestine is GLUT5. J Biol Chem 1992;267: 14523-6.

30 Rand EB, De Paoli AM, Davidson NO, et al. Sequence, tissue distribution, and functional characterization of the rat fructose transporter GLUT5. Am J Physiol 1993;264:G1 169-76. 
31 Shu R, David ES, Ferraris SP. Dietary fructose enhances intestinal fructose transport and GLUT5 expression in weaning rats. Am J Physiol 1997;272:G446-53

32 Scott J, Hounsell E, Feizi T, et al. Analysis of microvillus membrane from jejunum of prednisolone-treated rats. Cell Biol Int Rep 1980;4:814.

33 Batt RM, Scott J. Response of the small intestinal mucosa to oral glucocorticoids. Scand J Gastoenterol 1982;74:75-88.

34 Lebenthal E, Sunshine P, Kretchner N. Effect of carbohydrate and corticosteroid on activity of a-glucosidases in intestine of the infant rat. $J$ Clin Invest 1972:51:1244-50.

35 Lofberg R, Danielson A, Salde L. Oral budesonide in active Crohn's disease. Aliment Pharm Ther 1993;7:611-16.

36 Greenberg GR, Feagan BG, Martin F, et al. Oral budesonide for active Crohn's disease. N Engl J Med 1994;331:836-41.

37 Rutgeerts $\mathbf{P}$, Lofberg $\mathrm{R}$, Malchow $\mathrm{H}$. A comparison of budesonide with prednisolone for active Crohn's disease. N Engl J Med 1994;331:842-5.

38 Thiesen A, Thomson ABR. Older systemic and newer topical glucocorticosteroids and the gastrointestinal tract. Aliment Pharm Ther 1996; 10:487-96.

39 Thiesen A, Wild G, Thomson ABR. The adaptive effect of locally and systemically acting glucocorticosteroids on intestinal nutrient transport in rats is influenced by dietary lipids. Can J Gastroenterol 1996;10:15A.

40 Park JHY, McCusker RH, Mohammadpour H, et al. Dexamethasone inhibits mucosal adaptation. Am J Physiol 1994:266:G497-503.

41 Boyd AJ, Sherman IA, Saibil FG. Effects of plain and controlled-ilea-release budesonide formulations in experimental ileitis. Scand J Gastroenterol 1995;30:974-81.

42 Ozcay N, Fryer J, Grant D, et al. Budesonide, a locally acting steroid, prevents graft rejection in a rat model of intestinal transplantation. Transplantation 1997;63:1220-5

43 Thomson ABR, O'Brien BD. Uptake of cholesterol into rabbit jejunum using three in vitro techniques: importance of bile acid micelles and unstirred layer resistance. Am J Physiol 1981;241:G270-4.
44 Perin N, Keelan M, Jarocka-Cyrta E, et al. Ontogeny of intestinal adaptation in rats in response to isocaloric changes in dietary lipids. Am J Physiol 1997;273:G713-20.

45 Keelan M, Cheeseman CL, Clandinin MT, et al. Intestinal morphology and transport after ileal resection in rats is modified by dietary fatty acids. Clin Invest Med 1996;9:63-70.

46 Bloom SR, Polak JM. The hormonal pattern of intestinal adaptation: a major role for enteroglucagon. Scand J Gastroenterol 1982;74:93-103.

47 Reimer RA, McBurney MI. Incretin expression and secretion is altered with dietary fibre in rats. Can J Gastroenterol 1996;10:15A.

48 Jeppesen PB, Hartmann B, Thulesen J, et al. Glucagon-like peptide 2 improves nutrient absorption and nutritional status in short-bowel patients with no colon. Gastroenterology 2001;120:806-15.

49 Warner BW. GLP-2 as therapy for the short-bowel syndrome. Gastroenterology 2001;120:1041-2.

50 Goyal A, Singh R, Swietlicki EA, et al. Characterization of rat epimorphin/sytaxin 2 expression suggests a role in crypt-villus epimorphin/sytaxin 2 expression suggests a role in cryf
morphogenesis. Am J Physiol 1998;275:G1 14-24.

51 Rubin DC, Swietlicki EA Wanf JL, et al. Regulation of PC4/TIS7 expression in adapting remnant intestine after resection. Am J Physiol 1998;275:G506-13

52 Sellin JH, Field M. Physiologic and pharmacologic effect of glucocorticoids on ion transport across rabbit ileal mucosa in vitro. J Clin Invest 1981:67:770-8.

53 Williamson RCN, Baver FLR, Ross JS, et al. Proximal enterectomy stimulates distal hyperplasia more than bypass or pancreatobiliary diversion. Gastroenterology 1978;74:16-23.

54 Williamson RCN. Intestinal adaptation. N Engl J Med 1982;298: 1393-402

55 Williamson RCN. Intestinal adaptation: factors that influence morphology. Scand J Gastroenterol 1982;17:21-9.

56 Brattsand R. Overview of newer glucocorticosteroid preparations for inflammatory bowel disease. Can J Gastroenterol 1990;4:407-14.

57 Hirsch JR, Loo DD, Wright EM. Regulation of Na+/glucose cotransporter expression by protein kinases in Xenopus laevis oocytes. J
Biol Chem 1996;271:14740-6. 